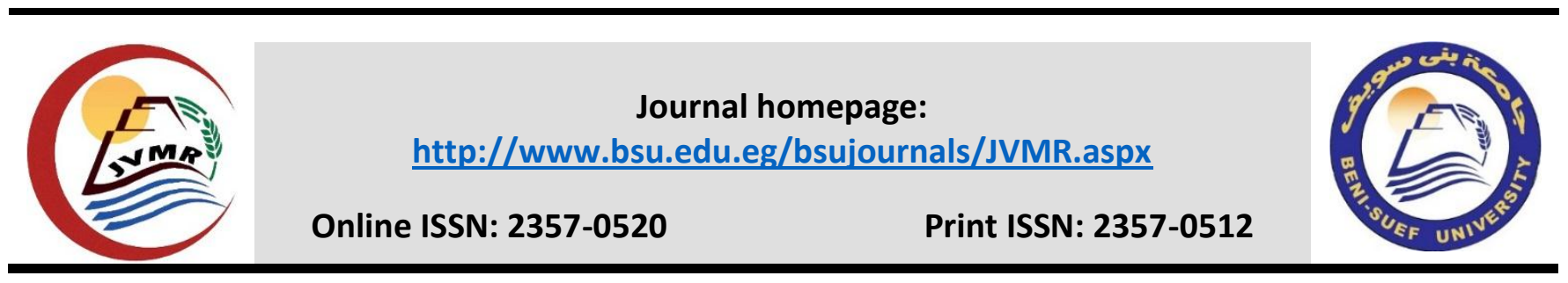

Original Research Article

\title{
Color Doppler ultrasound as an accurate and rapid tool for early pregnancy diagnosis in buffaloes
}

\author{
Ibrahim, S. S. ${ }^{1}$, El-Anwar, A.H.. ${ }^{1}$, Fadel, M.S. ${ }^{2}$ and Abd Elkarim, A. M. ${ }^{2}$ \\ 1 Department of Physiology, Faculty of Veterinary Medicine, Beni-Suef University, Beni-Suef 62511, Egypt. \\ 2, Diagnostic Imaging and Endoscopy Unit. Animal Reproduction Research Institute, Agriculture Research \\ Center.
}

\begin{abstract}
The objective was to determine the accuracy of color Doppler ultrasound for diagnosis of early pregnancy in buffaloes based on the evaluation of corpus luteum blood flow (CLBF) on days 20 and 21 after mating. Local Egyptian buffaloes, $(\mathrm{n}=12)$ during $3^{\text {rd }}$ and $4^{\text {th }}$ lactational season were kept in the farm of Animal Reproduction Research Institute (ARRI). The animals were divided into two groups, group A $(n=6)$ was mated naturally by a fertile bull during late estrus phase and group B $(n=6)$ was left. Animals underwent grayscale ultrasonography (US) to locate the CL , then color flow Doppler and power Doppler were activated to evaluate CLBF and pulsed wave Doppler to evaluate uterine blood flow on days $1,5,10,12,14,16,18,19,20,21,23,25,27,30$ after mating, using a portable, battery operated color Doppler and B-mode ultrasound scanner equipped with a $10-5 \mathrm{MHz}$, rectal transducer (M-turbo, Fujifilm sonosite, USA). Based on subjective (visual) and objective (Doppler parameters) corpus luteum blood flow (CLBF) evaluation. Animals in group A were classified as pregnant or non- pregnant on day 20 and day 21 after mating depending on CLBF. Blinded from results of the previous diagnosis, we performed a final pregnancy diagnosis using US to visualize the fetal heartbeat on day 30 after mating. Blood samples were collected from jugular vein after examination to determine by ELIZA kits, serum estradiol and progesterone concentration. The final pregnancy outcome on day 30 was retrospectively compared with the CLBF on days 20 and 21 diagnoses and then classified as true positive, true negative, false positive, and false negative. The sensitivity, specificity, positive predictive value, negative predictive value, and accuracy of the CLBF-d2021 test were calculated using specific equations.

The CLBF decreased markedly on days 20-21 in case of non-mated group (CL regression), while it remained constant or slightly increased in case of pregnant animals. Moreover the uterine blood flow markedly increased in case of non-mated group during the same period.

*Corresponding author. Department of Physiology, Faculty of Veterinary Medicine, Beni-Suef University, Beni-Suef 62511, Egypt.
\end{abstract}




\section{Introduction}

Pregnancy diagnosis has long been a routine activity in the management of cattle reproduction (Cowie, 1948 and Fricke and Lamb, 2005). The first purpose was to detect, as early as possible, animals that have failed to conceive, determine the cause of pregnancy failure, and to determine whether to rebreed (Fricke and Lamb, 2005) or cull such animals. Moreover the early pregnancy diagnosis and rapid rebreeding of non-pregnant animals reduces inter insemination intervals (Stevenson, 2005) and is part of the strategy used to improve reproductive performance (Fricke, 2002).

During the last few years, several techniques have been introduced in animal reproduction such as diagnostic ultrasound which has been available to the medical field since the early 1970, and then the development of real time or dynamic imaging in the late of 1970, which mad this powerful technology adapted for the study of internal reproductive tract in large domestic animal via trans rectal rout (Pierson et al., 1988), and give a great chance for understanding of the real-time dynamics of follicular development and early diagnosis of pregnancy depending on the early detection of the embryonic vesicle and the embryo proper with high accuracy on day 25 to day 26 after mating or artificial insemination.

Many previous reports have demonstrated that it is possible to diagnose pregnancy as early as day 20 after mating or AI using conventional grayscale ultrasonography ( Kastelic et al., 1988, 1989, 1991 and Pieterse et al., 1990), but the accuracies at early stages (d 21 to 25) are quite low (Pieterse et al., 1990 and Quintela et al., 2012).
The incorporation of new technologies in addition to the grayscale B-mode US, such as Doppler ultrasound, enables a more detailed assessment of the uterus, ovarian follicles, and corpus luteum. Color-flow mode (CFM) permits visualization of blood flow within tissues and structures based on the principles of the Doppler effect (Singh et al., 2003; Ginther, 2007 and Matsui and Miyamoto, 2009) and indirectly enables inferences to be made on the functional status of the tissue (Herzog et al., 2010).

The establishment and maintenance of pregnancy in cattle was dependent on the presence of a functional, active CL, as it produces a sufficient level of progesterone (Mann and Lamming, 1999; Lucy, 2001 and Parr et al., 2012). It has been suggested that color Doppler flow imaging could be useful for a more accurate early diagnosis of pregnancy in cattle (Quintela et al., 2012), based on evaluation of the CL blood flow, particularly if performed at 19 to $21 \mathrm{~d}$ after AI (Matsui and Miyamoto, 2009). A study of a CLBF-based pregnancy diagnosis test, in which a group of buffaloes are naturally mated by a fertile bull and checked for pregnancy at a later time, may be an optimal strategy for the use of color Doppler imaging in the routine reproductive management on dairy farms. Thus, the objective of this study was diagnosis of early pregnancy after the expected luteolysis on days 20 and 21 after mating, based on both the objective and subjective evaluation of CLBF by using the power Doppler ultrasonography.

\section{Material and Methods}

\section{Animals, Experimental Design:}

The study was conducted in the farm of Animal Reproduction Research Institute 
(ARRI), branch of Agriculture Research Center, using twelve $(n=12)$ multiparous, healthy, lactating and non-suckled Egyptian buffaloes of more than three months after parturition, divided into two equal groups $(n=6)$, the first group was naturally bred by a proven fertile bull during the late estrous phase, so it was named mated group and the other group lefted, so it was named non-mated group. Animals were maintained in a closed pen of $50 \mathrm{~m}^{2}$. A total mixed ration of $50 \%$ darawa, 30\% hay and $20 \%(8 \mathrm{~kg})$ concentrates, containing $15 \%$ crude protein/dry matter was fed daily in a group pen situation. During examination, the animals were kept in a stanchion and secured well and injected by a tranquilizer $0.75 \mathrm{ml}$ of xylazine hydrochloride (Xyla-ject ADWIA CO. S.A.E Egypt). The examination was done by single operator.

\section{Ultrasonography:}

Ultrasonography was performed during days $1,5,10,12,14,16,18,19,20,21,23,25,27,30$ after mating or after day of estrus (day of mating). The day of ovulation was designated as day 1. Each examination took $30 \mathrm{~min}$, by a single operator. Days 20 and 21 were considered the critical days for the evaluations based on the expected time of luteolysis in buffalo. We decided that an earlier evaluation (d17-18) would be of limited use because previous studies have reported a transient increase in blood flow surrounding the CL during the initiation of luteolysis (Miyamoto et al., 2005 and Ginther et al., 2007) and the length of the luteal phase in non-pregnant cattle shows considerable variation (14 to $18 \mathrm{~d}$ ), (Forde et al., 2011). Later evaluations (after d 21) would also be confounded by the appearance of new corpus hemorrhagicum structures formed after possible ovulation. Ovaries of all of the animals enrolled in the study were scanned for CL identification and blood flow evaluation using a portable, battery operated and auto adapted color Doppler and Bmode ultrasound scanner equipped with a 10$5 \mathrm{MHz}$, linear-array transducer (Sonosite Mturbo, Fujifilm sonosite, USA). After CL localization by conventional B-mode US, the power Doppler was activated and the blood flow over the entire CL structure were visually evaluated. This subjective evaluation took into consideration the amount of colored pixels within the luteal tissue, which was considered to be an indicator of CL functionality or regression. In addition to the real-time visual evaluation, the images of the CLBF was saved on the machine hard disc for further objective evaluations. Ultrasound images were exported to a computer and a computer-based image analysis program (image $\mathrm{j}$ software program) (Acosta et al., 2002), which determine the total CL area measured by pixel and the colored area within the CL tissue measured by pixel, these parameters were used as indicators for the CL diameter and CLBF respectively.

During Doppler ultrasonographic examinations, the uterine blood flow was scanned by using pulsed wave Doppler on the middle uterine artery which was located by following its origin from the internal iliac artery which originated directly from the abdominal aorta, (Bollwein et al., 2000). Time-averaged maximum velocity (TAMV) and resistant index (RI) was measured automatically and used as uterine blood flow indicators (Dudweisus, 1995 and Dickey, 1997).

\section{Blood Sampling:}

The blood samples were obtained from the jugular vein just after ultrasound examination, left for agglutination then they were centrifuged at $3000 \mathrm{r} / \mathrm{m}$ for $10 \mathrm{~min}$, the serum was separated and frozen at $-20^{\circ} \mathrm{C}$.

\section{Hormone assay:}

Serum progesterone and estradiol were estimated using a commercial enzyme-linked immunosorbent assay (ELISA) kit (Ridgeway Scientific, Alvington, Gloucestershire, UK). 
Sensitivity of the assay was $0.1 \mathrm{ng} / \mathrm{ml}$; intraand inter-assay variation coefficients were $6.2 \%$ and $9.5 \%$ respectively.

\section{Statistical analysis:}

Statistical analyses were performed for the uterine blood flow parameters TAMV, and RI, by using one way anova (SPSS) statical analysis program. Geometric means and geometric standard deviations were calculated. Post-hoc multiple pairwise comparisons were done according with a bonferroni adjustment of error rate. Serum progesterone concentrations, $\mathrm{CL}$ area and CL colored area were statistically analyzed by one way anova (SPSS), Those measurements were compared using the correlation coefficient (Pearson's correlation) and assuming $\mathrm{P}<0.05$ as the level of significance.

\section{Data Analysis:}

Retrospective analysis assembled information from both the predictive pregnancy diagnosis (CLBF-d20-21) and the final pregnancy outcome for data analyses. Numbers of true positive (TP), true negative (TN), false positive (FP), and false negative (FN) results were calculated to evaluate the CLBF test performance parameters. Sensitivities (Se) and Specificities (Sp), as defined by (Yerushalmy, 1947), were calculated using the average TP, $\mathrm{TN}$, FP, and FN. The following equations were used to calculate each parameter: $\mathrm{Se}=\mathrm{TP} /(\mathrm{TP}$ $+\mathrm{FN}), \mathrm{Sp}=\mathrm{TN} /(\mathrm{FP}+\mathrm{TN})$, and $\mathrm{ACC}=(\mathrm{TP}+$ $\mathrm{TN}) / \mathrm{n}$.

\section{Results}

The luteal blood flow in mated and nonmated group as shown in table (1): show a gradual increase after ovulation (day 1) till day 12 after mating during which the highest blood flow was observed. After that the blood flow slightly increased and decreased till day 19 then it shows a sharp decrease (regression phase) in case of non-mated group till day of estrus during which the lowest blood flow was observed. In mated group, the luteal blood flow remains constant or slightly increased till day 30 after mating, this increase in luteal blood flow observed in almost of cases except in one case where the blood flow decreases sharply at day 23 after mating (long diestrus phase). In respect to the previously mentioned results the pregnancy was assured in case of mated group on day 30 after mating by the use of grey scale ultrasound by observing the embryo and the embryonic vesicle, also by the use of color flow mapping, by observing the cardiac, extracadiac and the umbilical blood flow. The luteal blood flow at day 16 to day19 was variable among animals in both groups, so the luteal blood flow was not used as a diagnostic test during this period, also it was not used after day 21 as we observed a great confusion between blood flow of corpus heamoragicum in non-mated group and CL of pregnancy in case of mated group.

The accuracy of this test was $91.6 \%$, the specificity was $85 \%$, and the sensitivity was $100 \%$. The true positive value was $(n=5)$, false positive was $(n=1)$ and true negative $(n=6)$ and false negative $(n=0)$.

The correlation between luteal blood flow and progesterone concentration in the blood was positive $(\mathrm{r}=.71)$ also there were positive correlation between luteal blood flow and the CL diameter (total area) $(\mathrm{r}=.92)$ and also between luteal diameter and progesterone concentration $(\mathrm{r}=.74)$.

The uterine blood flow in both groups as shown in table (2): was similar till day 13 then it increases in dominant uterine artery of mated group from day 14 to day 18 , while in nonmated group it remains constant till day 17 and day 18 during which it decreases then it increased again before the onset of the estrus signs at which the highest uterine blood flow was observed, while in mated group it returns to values similar to that as day 13 and remain constant till day 25 then it shows a sharp increase till day 30 after mating. The uterine 
blood flow was variable among animals but the overall average was as discussed. a strong positive correlations between TAMV and estrogen concentration $(r=0.8)$ and there was a negative correlations between RI parameter and estrogen concentrations $(\mathrm{r}=-0.63)$ in non-mated group, and in mated group correlation between blood flow parameters (RI, and TAMV) of the dominant uterine artery during early pregnancy was similar to that of non-pregnant animals, where there was negative correlation between RI and TAMV ( $\mathrm{r}=-0.71)$.

Table (1): Luteal blood flow of mated and non-mated group. (Mean \pm SD).

\begin{tabular}{|c|c|c|c|c|c|c|}
\hline \multirow[t]{2}{*}{ Parameter } & \multicolumn{2}{|c|}{$\begin{array}{l}\text { Luteal blood flow } \\
\text { indicators } \\
\text { Of mated group }\end{array}$} & & \multicolumn{3}{|c|}{$\begin{array}{l}\text { Luteal blood flow indicators of non-mated } \\
\text { group }\end{array}$} \\
\hline & $\begin{array}{c}\text { CL area } \\
\text { (pixel) }\end{array}$ & $\begin{array}{l}\text { CL colored } \\
\text { area(pixel) }\end{array}$ & $\begin{array}{l}\text { Progesterone } \\
(\mathrm{ng} / \mathrm{ml})\end{array}$ & $\begin{array}{c}\text { CL area } \\
\text { (pixel) }\end{array}$ & $\begin{array}{l}\text { CL colored } \\
\text { area (pixel) }\end{array}$ & $\begin{array}{l}\text { Progesterone } \\
(\mathrm{ng} / \mathrm{ml})\end{array}$ \\
\hline 1 & $8113 \pm 813^{b}$ & $2838 \pm 222^{a}$ & $0.96 \pm .7^{\mathrm{c}}$ & $7325 \pm 1127^{\mathrm{C}}$ & $2464 \pm 25^{\mathrm{e}}$ & $0.81 \pm .5^{\mathrm{d}}$ \\
\hline 5 & $13707 \pm 414^{\mathrm{a}}$ & $4249 \pm 281^{a}$ & $5.78 \pm 1.1^{b}$ & $12992 \pm 143^{b}$ & $4143 \pm 222^{c}$ & $5.17 \pm 1.5^{\mathrm{c}}$ \\
\hline 10 & $16247 \pm 1366^{\mathrm{a}}$ & $4861 \pm 48^{\mathrm{a}}$ & $10.63 \pm 1.9^{\mathrm{a}}$ & $16416 \pm 2319^{a}$ & $4728 \pm 360^{b}$ & $11.28 \pm 3^{b}$ \\
\hline 12 & $16834 \pm 1690^{\mathrm{a}}$ & $5134 \pm 210^{\mathrm{a}}$ & $16.88 \pm 6.6^{\mathrm{a}}$ & $16699 \pm 2004^{\mathrm{a}}$ & $5119 \pm 221^{\mathrm{a}}$ & $15.59 \pm 3.1^{\mathrm{a}}$ \\
\hline 14 & $16925 \pm 1584^{\mathrm{a}}$ & $4900 \pm 139^{a}$ & $15.36 \pm 2.4^{\mathrm{a}}$ & $14799 \pm 2655^{\mathrm{a}}$ & $4894 \pm 155^{\mathrm{a}}$ & $15.55 \pm 2.4^{\mathrm{a}}$ \\
\hline 16 & $16501 \pm 1284^{\mathrm{a}}$ & $5123 \pm 189^{a}$ & $17.98 \pm 4.5^{\mathrm{a}}$ & $14896 \pm 2346^{\mathrm{a}}$ & $4802 \pm 190^{b}$ & $9.02 \pm 8.6^{b}$ \\
\hline 18 & $15476 \pm 758^{\mathrm{a}}$ & $4381 \pm 233^{a}$ & $15.32 \pm .9^{\mathrm{a}}$ & $11547 \pm 758^{b}$ & $4595 \pm 345^{\mathrm{ab}}$ & $9.1 \pm 3.7^{b}$ \\
\hline 19 & $16968 \pm 1398^{\mathrm{a}}$ & $4253 \pm 356^{\mathrm{a}}$ & $18.06 \pm 1.7^{\mathrm{a}}$ & $11102 \pm 1548^{b}$ & $2889 \pm 547^{d}$ & $2.77 \pm 2.7^{c}$ \\
\hline 20 & $\begin{array}{l}17607 \pm 1311 \\
\text { a }\end{array}$ & $4647 \pm 314^{\mathrm{a}}$ & $18 \pm 2^{\mathrm{a}}$ & $9797 \pm 1198^{b}$ & $1950 \pm 210^{\mathrm{f}}$ & $1.98 \pm 1.3^{\mathrm{d}}$ \\
\hline 21 & $17507 \pm 949^{\mathrm{a}}$ & $4910 \pm 553^{a}$ & $16.9 \pm 3.8^{\mathrm{a}}$ & $7701 \pm 897^{\mathrm{C}}$ & $1242 \pm 132^{g}$ & $1.58 \pm .8^{\mathrm{d}}$ \\
\hline
\end{tabular}




\begin{tabular}{|l|l|l|l|}
\hline 23 & $17432 \pm 1280^{\mathrm{a}}$ & $4837 \pm 480^{\mathrm{a}}$ & $18 \pm 2.6^{\mathrm{a}}$ \\
\hline 24 & $17283 \pm 1357^{\mathrm{a}}$ & $4734 \pm 277^{\mathrm{a}}$ & $18.01 \pm 1.2^{\mathrm{a}}$ \\
\hline 25 & $17098 \pm 1780^{\mathrm{a}}$ & $4787 \pm 264^{\mathrm{a}}$ & $16.42 \pm 1.3^{\mathrm{a}}$ \\
\hline 27 & $16753 \pm 1593^{\mathrm{a}}$ & $4704 \pm 199^{\mathrm{a}}$ & $17.7 \pm 3.6^{\mathrm{a}}$ \\
\hline 30 & $17701 \pm 1817^{\mathrm{a}}$ & $5002 \pm 208^{\mathrm{a}}$ & $16.5 \pm 1.2^{\mathrm{a}}$ \\
\hline
\end{tabular}

Data having different superscript letters in the same column are significantly different $(\mathrm{P}<0.05)$.

SD: Standard deviation.

Table (2): Uterine arterial blood flow of mated and non-mated group. (Mean \pm SD).

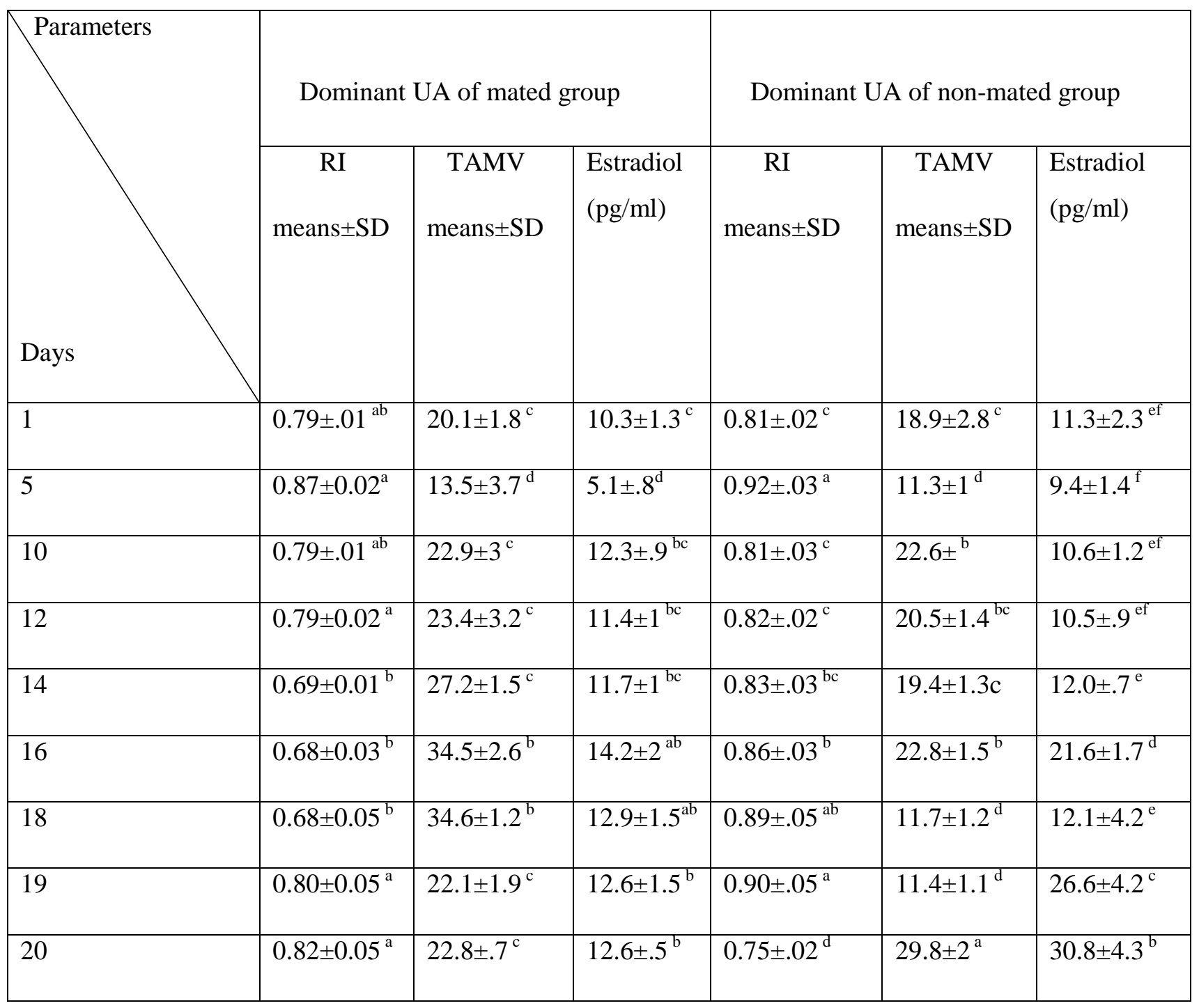


JOURNAL OF VETERINARY MEDICAL RESEARCH 2017, 24 (2 ): 286 - 302

\begin{tabular}{|l|l|l|l|l|l|l|}
\hline 21 & $0.82 \pm 0.04^{\mathrm{a}}$ & $23.5 \pm 2.9^{\mathrm{c}}$ & $12.6 \pm 1.6^{\mathrm{b}}$ & $0.72 \pm .02^{\mathrm{c}}$ & $32.0 \pm 2.6^{\mathrm{a}}$ & $33.8 \pm 2.1^{\mathrm{a}}$ \\
\hline 23 & $0.82 \pm 0.02^{\mathrm{a}}$ & $21.4 \pm 1.7^{\mathrm{c}}$ & $14.9 \pm 5.2^{\mathrm{a}}$ & - & - & - \\
\hline 25 & $0.71 \pm 0.04^{\mathrm{b}}$ & $37.6 \pm 4.7^{\mathrm{b}}$ & $12.5 \pm .3^{\mathrm{b}}$ & - & - & - \\
\hline 27 & $0.70 \pm 0.06^{\mathrm{b}}$ & $39.5 \pm 5.1^{\mathrm{b}}$ & $12.9 \pm 1.4^{\mathrm{ab}}$ & - & - & - \\
\hline 30 & $0.65 \pm 0.03^{\mathrm{b}}$ & $48 \pm 3.6^{\mathrm{a}}$ & $12.2 \pm 1.2^{\mathrm{bc}}$ & - & - & - \\
\hline
\end{tabular}

Data having different superscript letters in the same column are significantly different $(\mathrm{P}<0.05)$.

SD: Standard deviation.

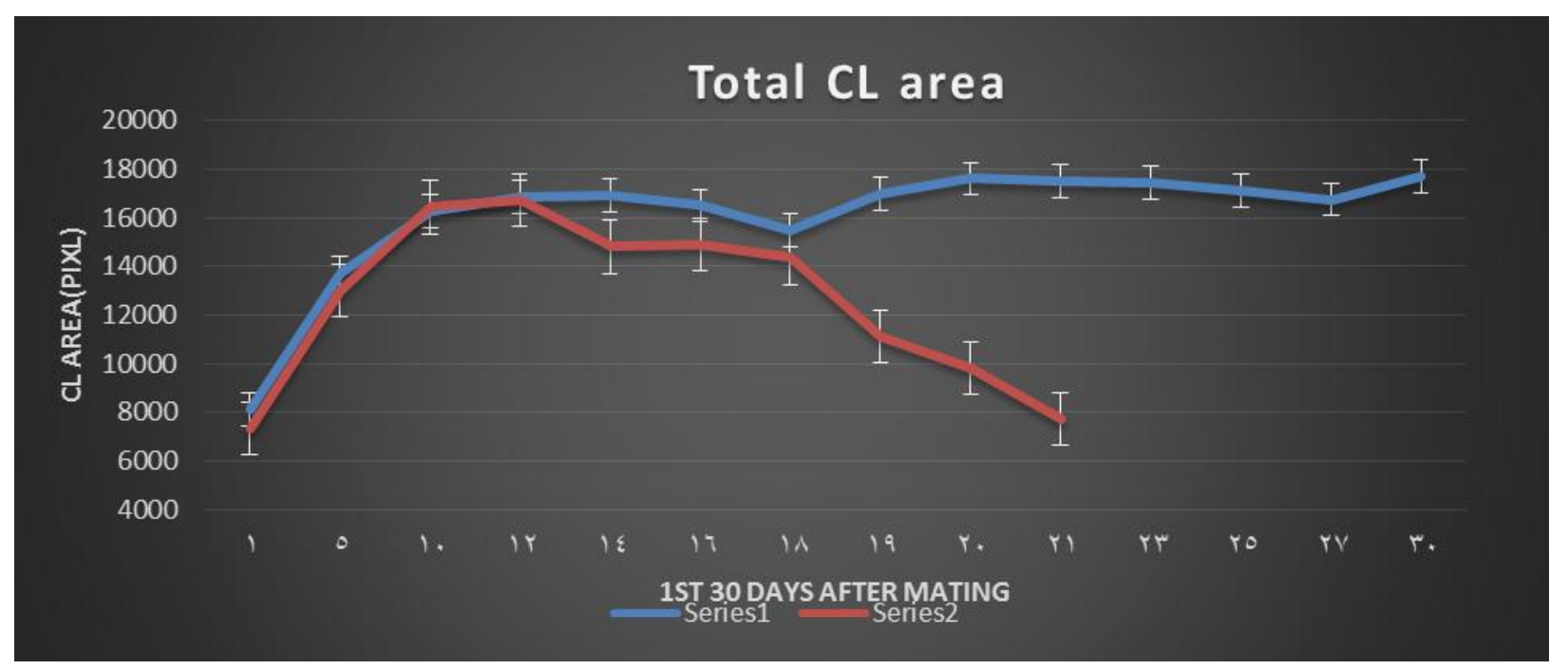

Fig (1): CL area during days after mating in case of mated and after estrus in case of non-mated groups. CLBF was similar in both groups till day 19 during which it remain constant or slightly increase in pregnant animals while it decreased sharply in non-mated group. 


\section{$\mathrm{CL}$ colored area}

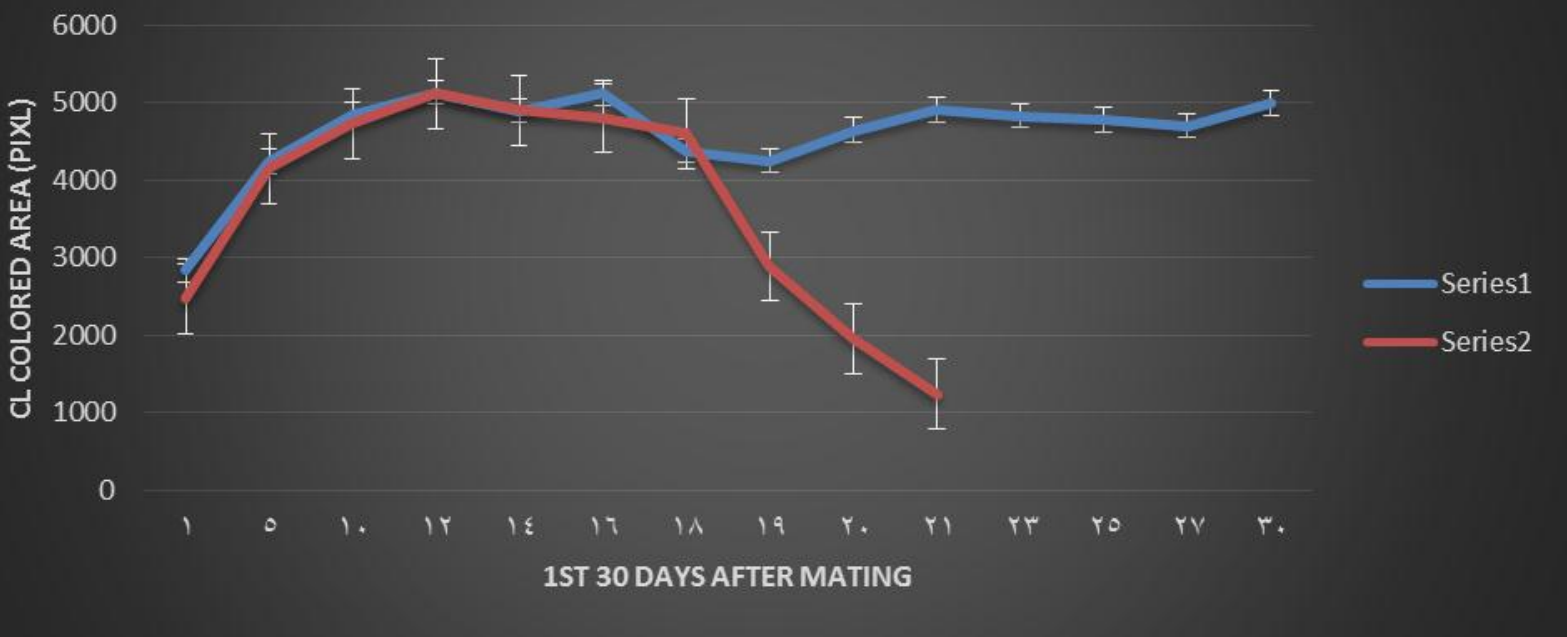

Fig (2): CL colored area during days after mating in case of mated and days after estrus in case of nonmated groups. CLBF was similar in both groups till day 19 during which it remain constant or slightly increase in pregnant animals while it decreased sharply in non-mated group

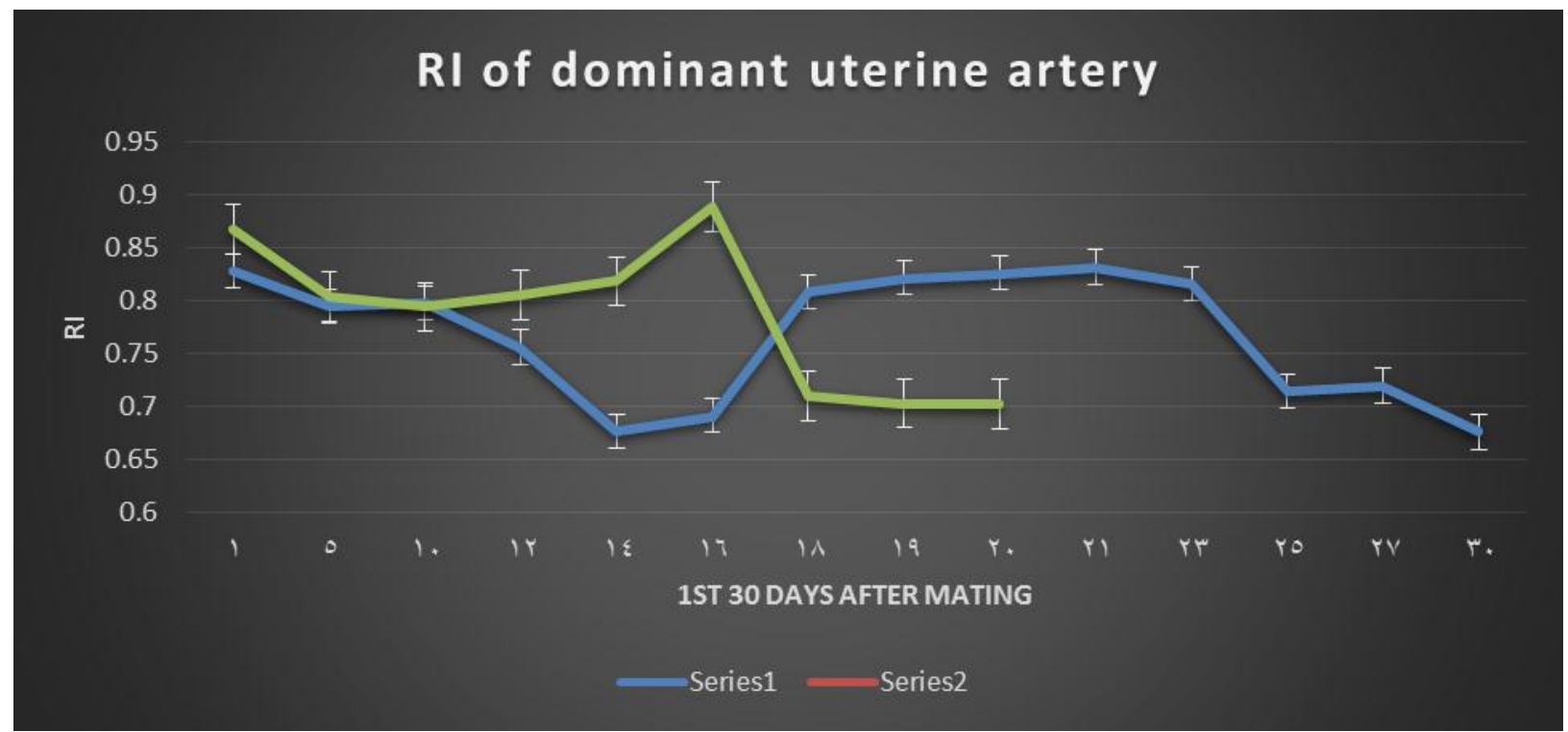

Fig (3): Uterine blood flow measured indirectly by the resistant index parameter (RI) during days after mating in case of mated group and after estrus in non-mated group. 


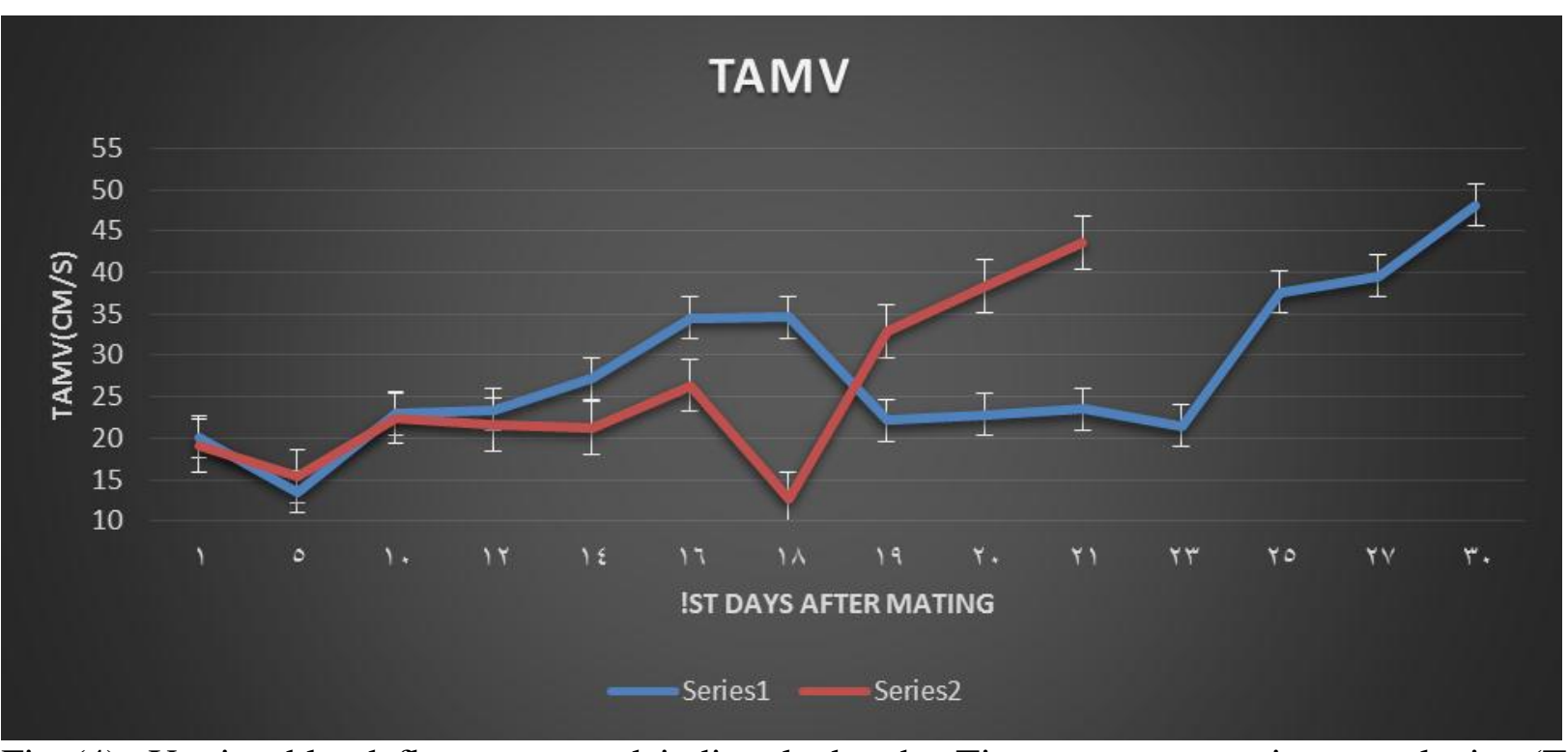

Fig (4): Uterine blood flow measured indirectly by the Time average maximum velocity (TAMV) parameter during days after mating in case of mated group and estrus in non-mated groups.

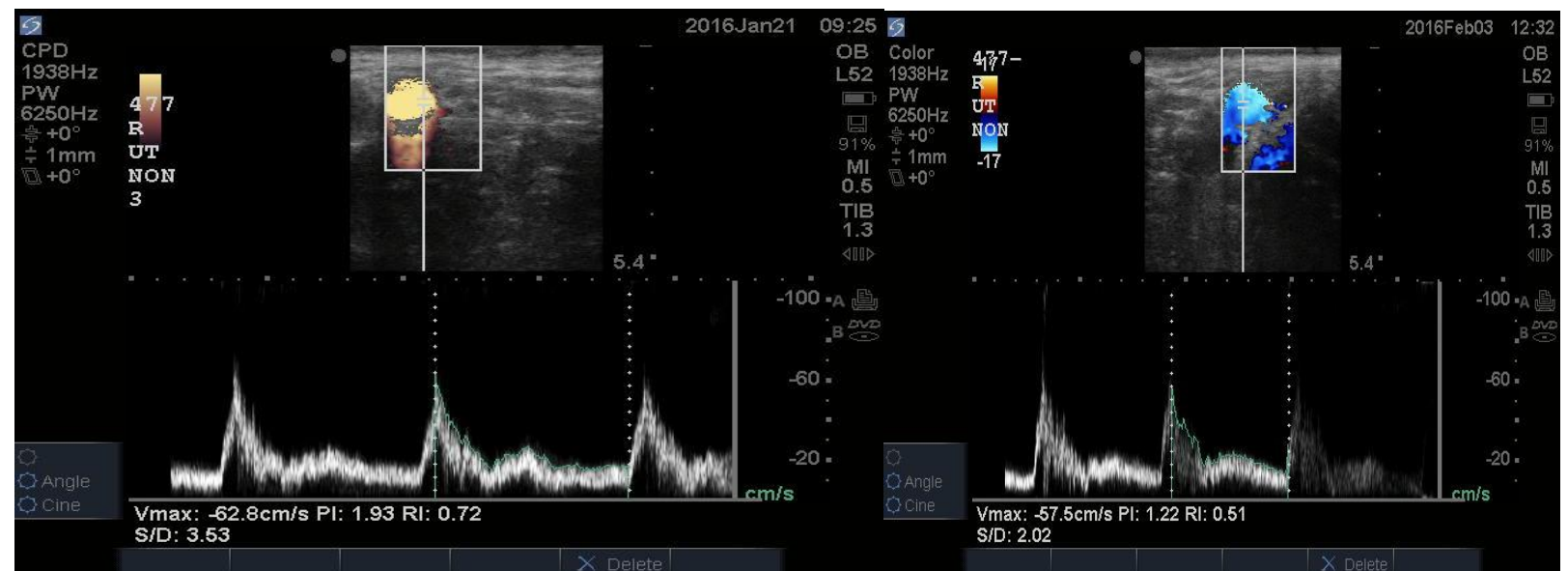

Fig (5): Uterine blood flow by pulsed wave Doppler of dominant uterine artery during days 20 and 21 after estrus expressions in non-mated group showing a sharp increases in TAMV and a sharp decreases in RI parameter. 


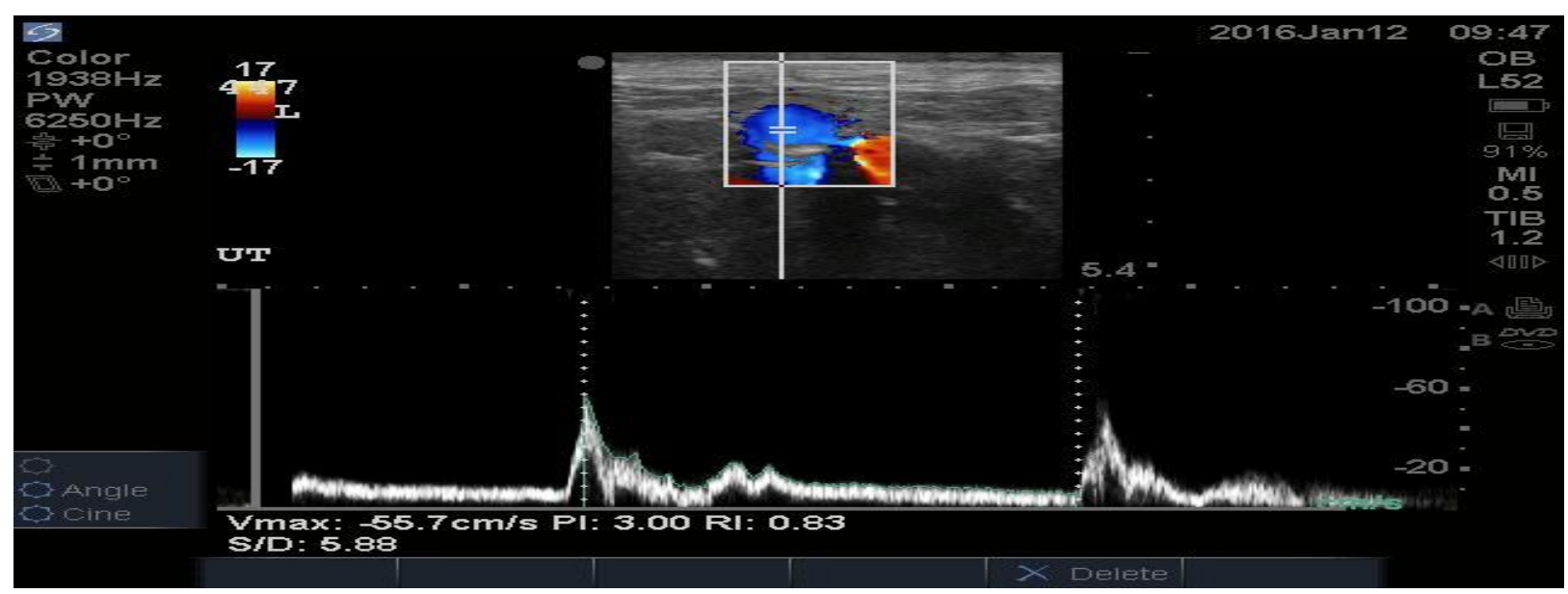

Fig (6): Uterine blood flow by pulsed wave Doppler of uterine artery during days 20, 21 after mating in mated group showing a moderate increases in TAMV and a moderate decreases in RI parameter.

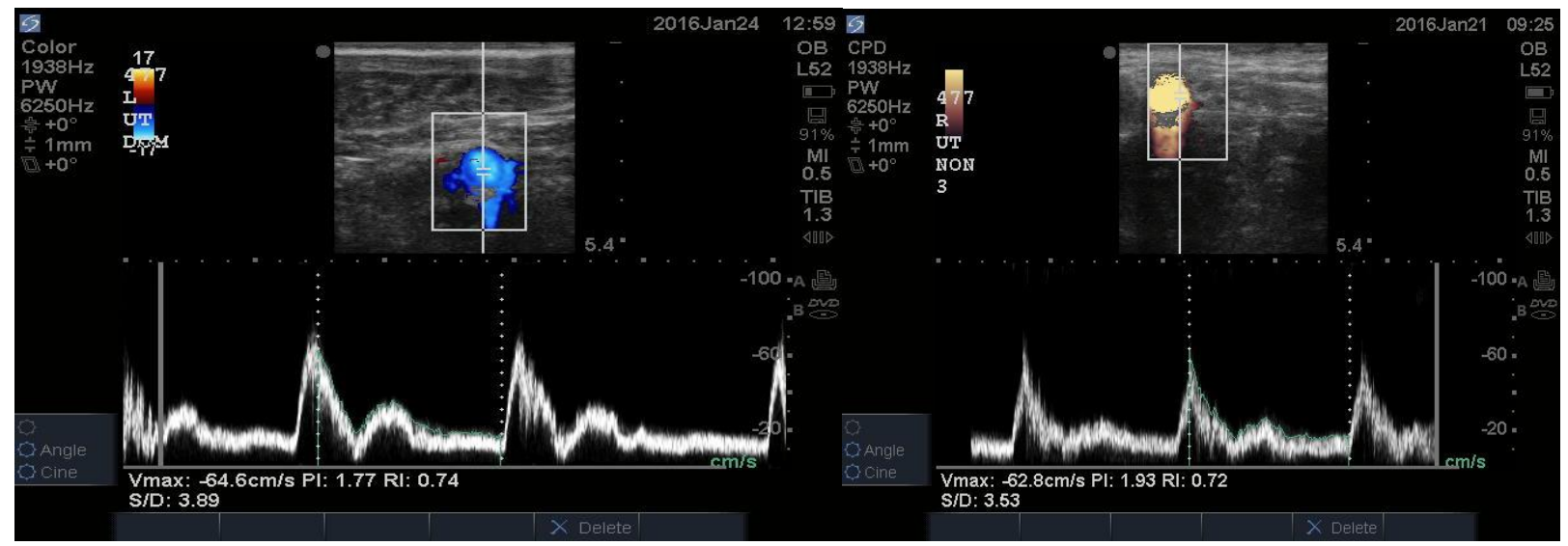

Day 25

Fig (7): Uterine blood flow by pulsed wave Doppler of uterine artery during days 25,28 after mating in mated group showing a sharp increases in TAMV and a sharp decreases in RI parameter. 


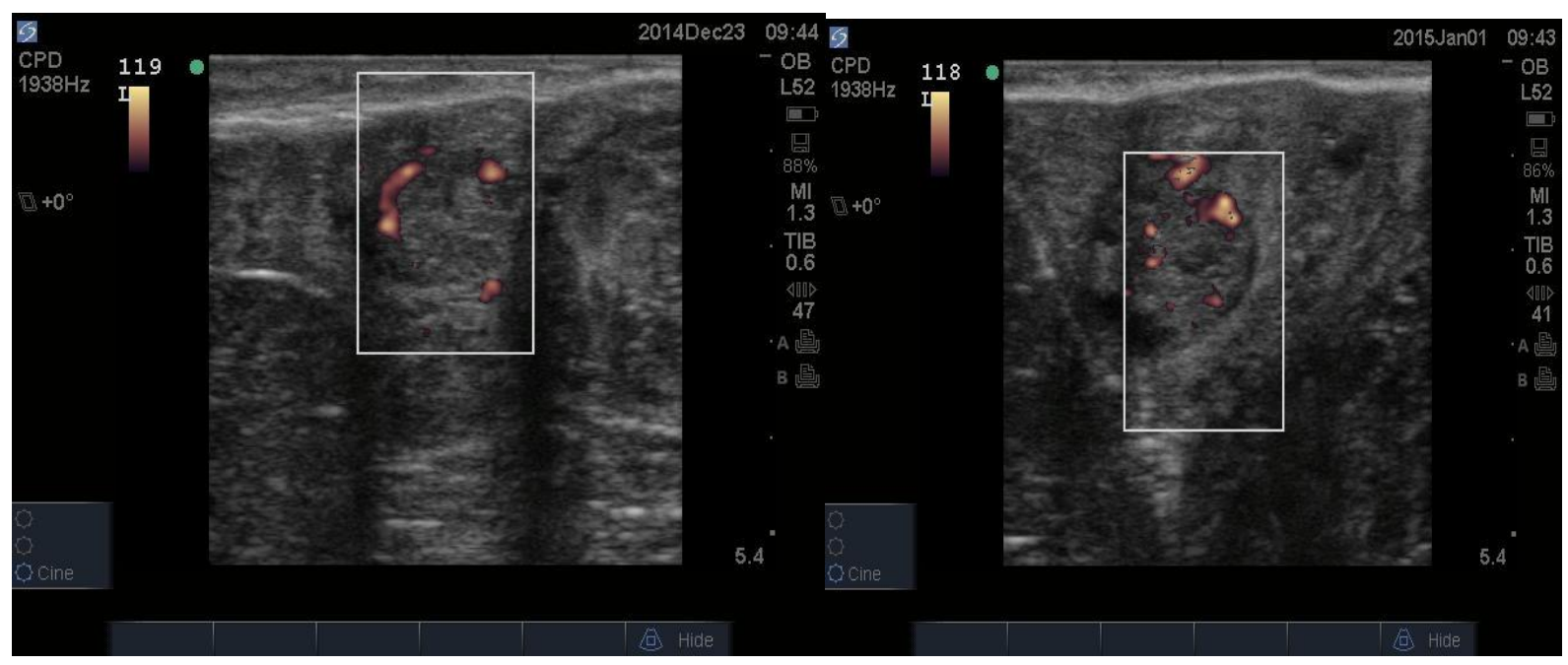

Day 20

Day 21

Fig (8): Luteal blood flow by power Doppler during days 20, 21 after estrus expression in case of non-mated group, showing a sharp decreases in LBF.

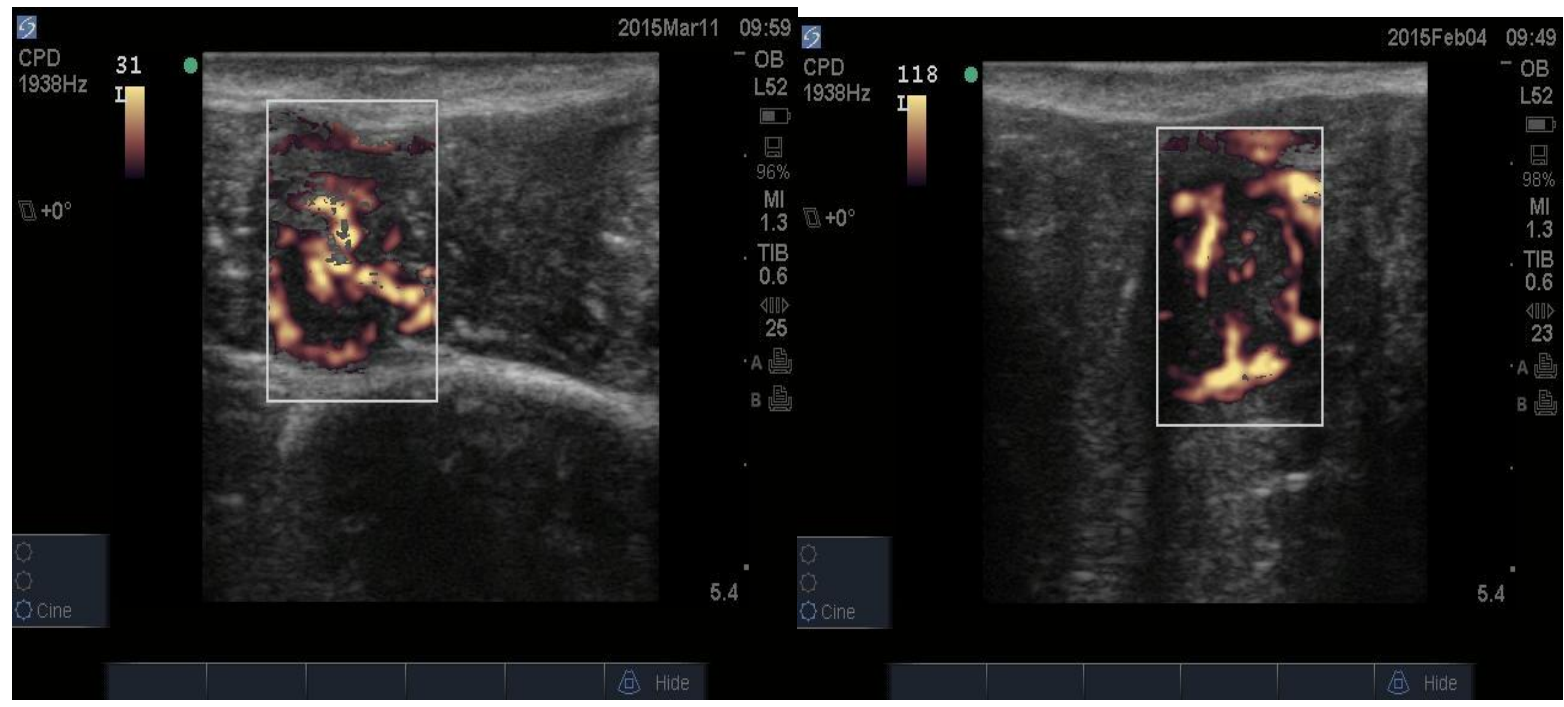

Day 20

Day 21

Fig (9): Luteal blood flow by power Doppler during days 20, 21 after mating in case of mated group, showing increased LBF.

\section{Discussion}

Early pregnancy diagnoses is essential for optimal reproductive management on dairy farms and for reducing the number of days open and calving intervals. In the current study, as suggested by other authors (Utt et al., 2009; Herzog et al., 2010 and Quintela et al., 2012), it was hypothesized that luteal blood flow, assessed using color Doppler ultrasound, would 
be a reliable diagnostic test of pregnancy when performed at 20 to $21 \mathrm{~d}$ after mating.

In the present study, evaluation of luteal blood flow was based on both visual (subjective) and CLBF parameters (objective) evaluation, which was similar to those reported by (Utt et al., 2009; Herzog et al., 2010 and Quintela et al., 2012), while, (Fonseca et al., 2013), depending only on the visual evaluation of the CLBF, which it is less time consuming and easier to incorporate into the reproductive management routine. Moreover different groups have evaluated CLBF in cattle by measuring the Doppler signal area, the ratio Doppler signal area: CLarea, or colored pixel intensity in the Doppler area in previously selected and recorded images (Acosta et al., 2002; Herzog et al., 2010 and Shrestha et al., 2010), although these approaches resulted in objective measures of CLBF, the necessity of postacquisition image processing limits real-time decisions. Furthermore, a strong agreement between objective and subjective evaluations of CLBF has previously been reported (Ginther et al., 2007).

In the current study we have demonstrated that the CLBF- d20-21test characterized by high Sensitivity (Se) (100\%), high Specificity (Sp) (85\%) and high accuracy (91.6\%). Come in agreement with our results those reported by Fonseca et al., (2013), who demonstrated that the CLBF-d20 test was characterized by high Se (99\%), medium Sp (53.7\%) and, most importantly, high NPV (98.5\%). The authors added that, With respect to accuracy, CLBF-d20 was as accurate as plasma P4 measurements for early diagnosis of pregnancy on d $20 \quad(74.8$ vs. $75.4 \%$, respectively), which were later determined using the gold standard (US-d30) which was similar with our results too.

On the other hand to our results, those reported by Herzog et al., (2011), who concluded that early pregnancy diagnosis by
CLBF was not an appropriate diagnostic tool for the early detection of pregnancy, this differences most likely related to the period within which pregnancy prediction was performed. The latter authors analyzed luteal blood flow on d 15 and 18, whereas the current study analyzed CLBF a few days later (d 20-21) when the differences between pregnant and non-pregnant animals are expected to be greater.

In the present study all animals in the second (non-bred) group show a sharp decrease in CLBF at days 20 and 21 after mating with high sensitivity and high specificity. In agreement to our results those reported by Fonseca et al., (2013), who revealed that prediction of pregnancy based on the CLBF at $20 \mathrm{~d}$ after AI with high Se and a medium Sp, moreover the accuracy of the CLBF-d20 diagnoses was higher for negative (NPV) than positive (PPV) cases (98.5 vs. $64.8 \%$, respectively). A greater concern was the likelihood of correctly identifying cattle as truly not pregnant to ensure that this test would be actually useful in an intensive reproductive management program. Also in the same line to our results Fricke and Lamb, (2005) and Romano et al., (2006), demonstrated that the major reason for diagnosing pregnancies early is to correctly identify non-pregnant animals. Also Quintela et al., (2012), revealed that there was a higher accuracy of CLBF-d20 for detecting non-pregnant than for detecting pregnant animals.

Incorrect CLBFd20 diagnoses may also occur in estrous cycles with extended luteal phases (i.e., delayed CL regression), the occurrence of which has previously been described in dairy cows (Giordano et al., 2012). That study also observed that $P 4$ concentrations before d 22 after TAI were not different between pregnant cows and those with an extended luteal phase most likely because the latter experienced embryonic loss after the period of maternal recognition of pregnancy. 
A pregnancy diagnostic test must be feasible in a practical routine in addition to being reliable and accurate. Blood collection and laboratory assays to determine plasma (Thirapatsukun et al., 1978) or milk (Pennington et al., 1976 and Gowan and Etches, 1979) P4 concentrations or to detect specific pregnancy-associated plasma proteins (Humblot et al., 1988 and Silva et al., 2007) have been used previously for pregnancy diagnosis in dairy cattle. Results, however, were contradictory and, therefore, of limited potential use in large herds. Moreover, the need for blood sampling, centrifugation, plasma separation, and lastly the laboratory assay itself made these tests complex, time consuming, and expensive.

In the present study, the CLBF-d2021 test is more accurate and reliable than early pregnancy diagnosis by conventional ultrasound before day 25. In agreement to our results are those reported by Pieterse et al., (1990); Romano et al., (2006) and Quintela et al., (2012), who revealed that grayscale B-mode US examinations for pregnancy before $\mathrm{d} 26$ to 28 have also been described as time consuming, of only fair reliability, and of limited accuracy In addition to the requirement for sketching the ovaries to detect the CL and the uterine horns to detect the embryonic vesicle, the presence of uterine mucus may hamper the operator in cows that are in proestrus or estrus phases (Pieterse et al., 1990; Kastelic et al., 1991 and Quintela et al., 2012).

In the present study, blood flow through the dominant uterine artery from day 20 to day 21 of non-mated animals highly increased (high TAMV and low RI), while in mated group, it shows a moderate increase similar to that observed on Day 13, and the blood flow to the non-dominant uterine artery remained constant. After that the blood flow progressively increased through the dominant uterine artery from day 25 to day 30 of pregnancy while the blood flow sharply decreased through the nondominant uterine artery.

In agreement with our study Ford et al., (1979) reported that by day19 of pregnancy blood flow throughout dominant uterine artery had returned to a values similar to that observed on day 13 and remain constant till day 25 of pregnancy. The same authors added that, from day 25 until day 30 of pregnancy blood flow pattern show progressive increase within the ipsilateral uterine artery while the blood flow within the contralateral uterine artery sharply decreased. Increased blood flow may be associated with implantation. Attachment of the bovine conceptus to the uterine wall is a gradual process with the first points of attachment occurring immediately around the embryo by Day 30 (Melton et al., 1951).

The CLBF at day 20-21 in buffaloes can be used as a diagnostic test for detection of early pregnancy with high accuracy and high specificity. The CLBF-d20-21test is more accurate and reliable than early pregnancy diagnosis by conventional ultrasound before day 25. CLBF-d20 was as accurate as plasma P4 measurements for early diagnosis of pregnancy on d 20.

\section{References:}

Acosta, T. J., Yoshizawa N., Ohtani M., and Miyamoto A. (2002): Local changes in blood flow within the early and midcycle corpus luteum after prostaglandin F2 $\alpha$ injection in the cow. Biol. Reprod. 66:651-658.

Bollwein H, Meyer HH, Maierl J, Weber F, Baumgartner U, Stolla R, (2000): Transrectal Doppler sonography of uterine blood flow. Theriogenology 53, 15411552 . 
Cowie, T. A. (1948): Pregnancy diagnosis tests: A review. Commonwealth Agricultural Bureaux Joint Publication, Great Britain 13:11-17.

Dickey RP, (1997): Doppler ultrasound investigation of uterine and ovarian blood flow in infertility and early pregnancy. Hum Reprod Update 3, 467-503.

Dudwiesus H, (1995): Physikalische Grundlagen. In: Sohn C (ed.), Ultraschall in Gyna" kologie und Geburtshilfe. Thieme, Stuttgart, New York, pp. 1-68.

Edmonson, A. J., Lean I. J., Weaver L. D., Farver T., and Webster G. (1989): A body condition scoring chart for Holstein dairy cows. J. Dairy Sci. 72:68-78.

Fonseca, J.F. Fernandes C.A.C., Palhao M.P., Viana J.H.M. (2013): Color Doppler flow imaging for the early detection of non-pregnant cattle at 20 days after timed artificial insemination. Journal of Dairy Science. 96:6461-6472.

Ford SP., Chenault JR., Echternkamp SE., (1979): Uterine blood flow of cows during the estrous cycle and early pregnancy: effect of the conceptus on the uterine blood supply. J Reprod Fertil 56, 53-62.

Forde, N., Beltman M. E., Lonergan P., Diskin M., Roche J. F., and Crowe M.
A. (2011): Estrous cycles in Bos taurus cattle. Anim. Reprod. Sci. 124:163-169.

Fricke, P. M. (2002): Scanning the futureUltrasonography as a reproductive management tool for dairy cattle. J. Dairy Sci. 85:1918- 1926.

Fricke, P. M., and Lamb G. C. (2005): Potential applications and pitfalls of reproductive ultrasonography in bovine practice. Vet. Clin. North Am. Food Anim. Pract. 21:419-436.

Ginther, O. J., (2007): Ultrasonic Imaging and Animal Reproduction: Color-Doppler Ultrasonography. Equiservices Publishing, Cross Plains, WI.

Ginther, O. J., Silva L. A., Araujo R. R., and Beg, M. A. (2007): Temporal associations among pulses of 13, 14-dihydro-15-ketoPGF2 $\alpha$, luteal blood flow, and luteolysis in cattle. Biol. Reprod. 76:506-513.

Giordano, J. O., Guenther J. N., Lopes G. Jr., and Fricke P. M. (2012): Changes in serum pregnancy-associated glycoprotein, pregnancy specific protein $\mathrm{B}$, and progesterone concentrations before and after induction of pregnancy loss in lactating dairy cows. J. Dairy Sci. 95:683697.

Gowan, E. W., and Etches R. J. (1979): A solid-phase radioimmunoassay for progesterone and its application to 
pregnancy diagnosis in the cow.

Theriogenology 12:327-343.

Herzog, K., Brockhan-Ludemann M., Kaske

M., Beindorff N., Paul V., Niemann H., and Bollwein H. (2010): Luteal blood flow is a more appropriate indicator for luteal function during the bovine estrous cycle than luteal size. Theriogenology 73:691-697.

Herzog, K., Voss C., Kastelic J. P., Beindorff N., Paul V., Niemann H., and Bollwein H. (2011): Luteal blood flow increases during the first three weeks of pregnancy in lactating dairy cows. Theriogenology 75:549-554.

Humblot, P., Camous S., Martal J., Charlery J., Jeanguyot N., Thibier M., and Sasser G. (1988): Diagnosis of pregnancy by radioimmunoassay of a pregnancyspecific protein in the plasma of dairy cows. Theriogenology 30:257-267.

Kastelic, J. P., Bergfelt D. R., and Ginther O. J. (1991): Ultrasonic detection of the conceptus and characterization of intrauterine fluid on days 10 to 22 in heifers. Theriogenology 35:569-581.

Kastelic, J. P., Curran S., and Ginther O. J. (1989): Accuracy of ultrasonography for pregnancy diagnosis on days 10 to 22 in heifers. Theriogenology 31:813-820.
Kastelic, J. P., Curran S., Pierson R. A., and Ginther O. J. (1988): Ultrasonic evaluation of the bovine conceptus. Theriogenology 29:39-54.

Lucy, M. C. (2001): Reproductive loss in highproducing dairy cattle: Where will it end? J. Dairy Sci. 84:1277-1293.

Mann, G. E., and Lamming G. E. (1999): Influence of progesterone during early pregnancy in cattle. Reprod. Domest. Anim. 34:269-274.

Matsui, M., and Miyamoto A. (2009): Evaluation of ovarian blood flow by colour Doppler ultrasound: Practical use for reproductive management in the cow. Vet. J. 181:232-240.

Melton, A. A., Berry R. O. and Butler O. D. (1 95 1): The interval between the time of ovulation and attachment of the bovine embryo. J. Anim. Sci. 1 0: 993.

Miyamoto, A., Shirasuna K., Wijayagunawardane M. P. B., Watanabe S., Hayashi M., Yamamoto D., Matsui M., and Acosta T. J.. (2005): Blood flow: A key regulatory component of corpus luteum function in the cow. Domest. Anim. Endocrinol. 29:329-339.

Parr, M. H., Mullen M. P., Crowe M. A., Roche J. F., Lonergan P., Evans A. C. O., and Diskin M. G. (2012): Relationship between pregnancy per 
artificial insemination and early luteal concentrations of progesterone and establishment of repeatability estimates for these traits in Holstein-Friesian heifers. J. Dairy Sci. 95:2390-2396.

Pennington, J. A., Spahr S. L., and Lodge J. R. (1976): Pregnancy diagnosis in dairy cattle by progesterone concentration in milk. J. Dairy Sci. 59:1528-1531.

Pierson, R.A., Kastelic, J.P. and Ginther, O.J. (1988): Basic Principles and Techniques for Trans-Rectal Ultrasonography in Cattle and Horses. Theriogenology 29: 3-20.

Pieterse, M. C., Szenci O., Willemse A. H., Bajcsy C. S. A., Dieleman S. J., and Taverne M. A. M. (1990): Early pregnancy diagnosis in cattle by means of linear-array real-time ultrasound scanning of the uterus and a qualitative and quantitative milk progesterone test. Theriogenology 33:697-707.

Quintela, L. A., Barrio M., Pena A. I., Becerra J. J., Cainzos J., Herradon P. G., and Diaz C. (2012): Use of ultrasound in the reproductive management of dairy cattle. Reprod. Domest. Anim. 47:34-44.

Romano, J. E., Thompson J. A., Forrest D. W., Westhusin M. E., Tomaszweski M. A., and Kraemer D. C. (2006): Early pregnancy diagnosis by transrectal ultrasonography in dairy cattle. Theriogenology 66:1034-1041.

Shrestha, H. K., Beg M. A., Imam S., and Ginther O. J. (2010): Luteal blood flow and concentrations of circulating progesterone and other hormones associated with a simulated pulse of 13 , 14-dihydro- 15-keto-prostaglandin F2 $\alpha$ in heifers. Reproduction 139:673-683.

Silva, E., Sterry R. A., Kolb D., Mathialagan N., McGrath M. F., Ballam J. M., and Fricke P. M. (2007): Accuracy of a pregnancy associated glycoprotein ELISA to determine pregnancy status of

Singh, J., Adams G. P., and Pierson R. A. (2003): Promise of new imaging technologies for assessing ovarian function. Anim. Reprod. Sci. 78:371-399.

Stevenson, J. S. (2005): Breeding strategies to optimize reproductive efficiency in dairy herds. Vet. Clin. North Am. Food Anim. Pract. 21:349-365.

Thirapatsukun, T., Entwistle K. W., and Gartner R. J. W. (1978): Plasma progesterone levels as an early pregnancy test in beef cattle. Theriogenology 9:323332.

Utt, M. D., Johnson III G. L., and Beal W. E. (2009): The evaluation of corpus luteum blood flow using color-flow Doppler 
JOURNAL OF VETERINARY MEDICAL RESEARCH 2017, 24 (2 ): 286 - 302

ultrasound for early pregnancy diagnosis in bovine embryo recipients. Theriogenology 71:707-715.

Yerushalmy, J. (1947): Statistical problems in assessing methods of medical diagnosis, with special reference to X-ray techniques. Public Health Rep. 62:14321449. 